\title{
APPLICATION CAD METHODS IN 3D CLOTHING DESIGN
}

\author{
Maja Jankoska
}

University "Ss. Cyril and Methodius" in Skopje, Faculty of Technology and Metallurgy, Department of Textile Engineering, North Macedonia

Professional paper

e-mail: maja@tmf.ukim.edu.mk

UDC: $687.2: 004.94$

doi: $10.5937 /$ tekstind2004031J

\begin{abstract}
Modeling virtual garments is known as a very laborious process, which includes designing 2D patterns, positioning, and sewing them in 3D, performing a physically-based simulation, and then iteratively adjusting patterns and parameters, repeating the process until the expected effect is achieved. The aim of this paper is to make a 2D pattern and 3D simulation of a men's shirt. First, the computer construction of the men's shirt model was made on a sketch-based, i.e. a 2D pattern is developed. Secondly, 2D pattern is developed by flattening 3D surface patches, then a 3D fine garment is formed directly based on the information of sewing relations and correspondence between $3 D$ surfaces and $2 D$ patterns. The method is able to design $3 D$ garments and 2D patterns efficiently and accurately.
\end{abstract}

Keywords: pattern design, 3D garment, sketch modeling, clothing simulation.

\section{PRIMENA CAD METODA U 3D DIZAJNU ODEĆE}

Apstrakt: Modeliranje virtuelne odeće poznato je kao vrlo naporan proces, koji uključuje dizajniranje 2D uzoraka, pozicioniranje i šivanje u 3D, izvođenje fizički zasnovane simulacije, a zatim iterativno prilagođavanje uzoraka i parametara, ponavljajući postupak dok se ne postigne očekivani efekat. Ciljovog rada je da se napravi 2D uzorak i 3D simulacija muške košulje. Prvo je komjuterska konstrukcija modela muške košulje napravljena na osnovu skica, tj. razvijen je 2D uzorak. Drugo, 2D uzorak se razvija izravnavanjem 3D površinskih slojeva, zatim se 3D fini odevni predmet formira direktno na osnovu informacija o relacijama šivenja i korespondencije između 3D površina i 2D uzoraka. Metoda je u stanju da efikasno i tačno dizajnira 3D odeću i 2D uzorke

Ključne reči: dizajn uzorka, 3D odeća, modeliranje skica, simulacija odeće.

\section{INTRODUCTION}

Garment CAD technology is the use of computer technology to assist in the design of garment products. Early garment CAD focused on 2D pattern drafting and modification. To release the heavy dependencies on pattern-masters' experience in $2 \mathrm{D}$ systems, $3 D$ garment $C A D$ methods with the technologies of human body measurement are studied and proposed as an alternative solution to non-expert users. The key techniques include 3D human body measurement and modeling, 3D garment design on digital human models, 3D draping simulation, and 2D pattern generation from $3 D$ space.

Sketch-based design methods provide a promising process of 3D garment design, which automatically creates a 3D garment model from user-sketched 2D silhouettes of the garment [1-2]. Wang et al. [3] presented a feature-based 3D garment design through 2D sketches. In this method, a feature template for creating a 3D garment is defined according to the features of a human model, and the profiles of the 3D garment are specified through 2D sketches. 3D cloth simulations are either geometrical based or physical based. Because of the contributions from the computer graphics community, the simulation accuracy and speed have been much improved in recent years [4, 5]. In the field of clothing and textiles, 3D simulation is considered to be of great potential for fit analysis, and a number of commercial clothing CAD systems have deployed 3D simulation modules. Typically, a 3D virtual fit model is firstly created and then the clothing patterns are virtually sewn around the 3D model as if the garment worn by the customer. The fit model 
can be customized based on customers' body dimensions. It can be an excellent tool for clothing product development because the costly sample making and fitting process can be reduced or completely eliminated, suggested by the software suppliers. However, there is no systematic investigation on the validity of 3D clothing simulation for fit analysis, especially in view of the fabric property diversity. A sensory test was used to identify the deviation of virtual garments from real garments based on body shape, yet a nonmainstream 3D simulation was adopted. The effectiveness of a mainstream 3D simulation system for pants fit evaluation was carried out by wear trial. It was found that the visual information of the silhouette of the overall pants was accurate, but not the information about fabrics [6]. Further investigation is required to identify the range of validity for fabric simulation. Much research has been conducted for 3D garment design and simulation. Liu et al. [7] presented a survey on CAD methods in 3D garment design. Turquin et al. [8] introduced a technique that allows the users to sketch garment contours directly onto a $3 \mathrm{D}$ human model, then a 3D garment surface is generated by computing the distance field around the human body. This method is mainly used to create a 3D garments for virtual characters, and it does not aim to generate patterns for real garment. Brouet et al. [9] studied for a 3D garment with complex features such as wrinkles, although a plausible 3D garment shape can be gotten, the shapes of the resulting $2 \mathrm{D}$ patterns tend to have somewhat wavy outlines, sub-optimal for actual manufacturing. Porterfield and Lamar [10] investigated how using 3D garment simulation to conduct fittings virtually might impact the interactive process of garment fitting. Lee and Park [11] provided suggestions for areas of improvement in 3D virtual fit simulation technology for increased adoption of the 3D technology for effective prototyping and quality assessment in the fashion industry. Lage and Ancutiene [12] investigated distance ease distribution

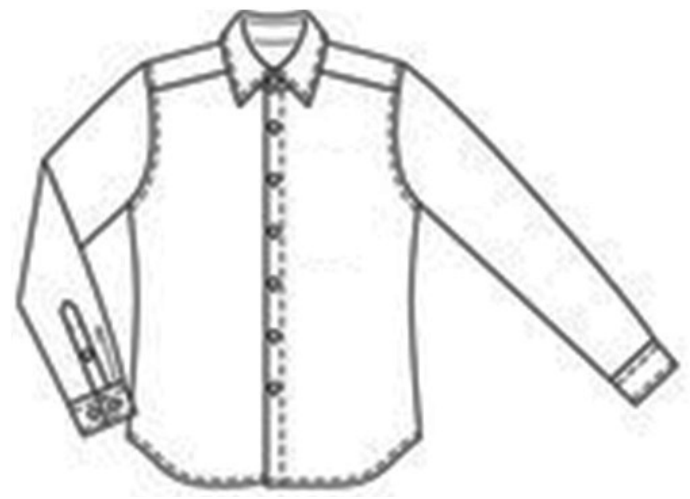

between straight shape virtual dress and 3D body in respect to fabrics mechanical (tensile, bending, shear) properties using virtual try-on software Modaris 3D Fit (CAD Lectra). Kim and LaBat [13] researched was to examine consumer experience and satisfaction of using 3D virtual simulation technology, especially for online shopping, and consumers' willingness to use the technology in the future. Wu et al. [14] have an exploratory study to analyzed the accuracy of 3D cloth simulation system so as to examine its validity and effectiveness in garment fit evaluation. Modeling virtual clothing where 2D and 3D digital technology is a modern tool is becoming a platform for the design, preparation and production of clothing. 3D virtualized technology reduces the number of samples, creates efficient production, and makes quick decisions, increases competitiveness, communication and e-sales [15].

The aim of this paper is to make a 2D pattern and 3D simulation of men's shirt. First, the construction of the men's shirt model was made on a sketch-based, i.e. a 2D pattern is developed. Secondly, a 2D pattern is developed by flattening 3D surface patches, then a 3D fine garment is formed directly based on the information of sewing relations and correspondence between $3 \mathrm{D}$ surfaces and 2D patterns.

\section{EXPERIMENTAL PART}

Figure 1 shows a technical sketch of a men's shirt. A computer construction of a men's shirt size 40 was made on the computer program Lectra Modaris. After that, with the Clo3D program 2D to 3D transformation was made, a simulation was made by sewing the parts, their fitting form to the avatar with arrangement points in blue colors. Then using a strain map, a 3D human body is represented by a triangular mesh, places that show a problem with a pattern such as not fit well, parts (front, back, sleeve or collar) are wide or tight or show some other deformation.

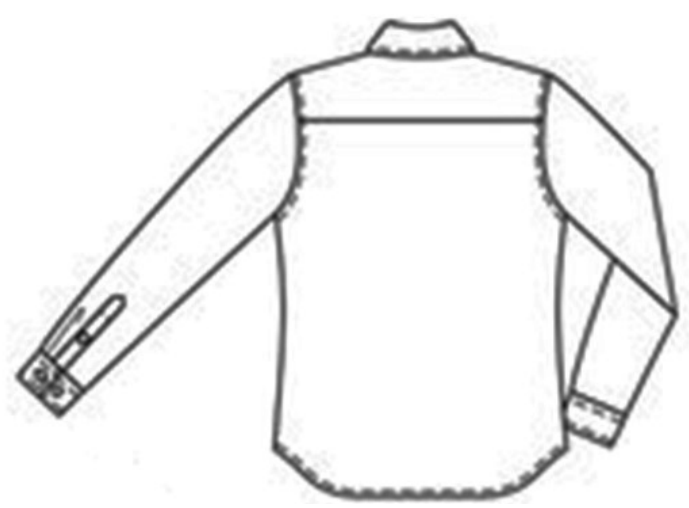

Figure 1: Technical sketch of men's shirt 
Based on this data, determined by a strain map where they are shown in red color, a correction of these parts of the deformations can be made immediately on the avatar, and corrected clothing is obtained. The mesh is made of triangles that must be the same size for the clothes to fit the avatar well, in the opposite would otherwise mean that something is not as it should be.

\section{RESULTS AND DISCUSSION}

Figure 2 shows the computer construction of a men's shirt on the Lectra Modaris program.

Based on a 3D human model, an initial 3D garment surface is automatically generated. Editable control curves are used to control the garment shape interactively and accurately, and the resulting garment can

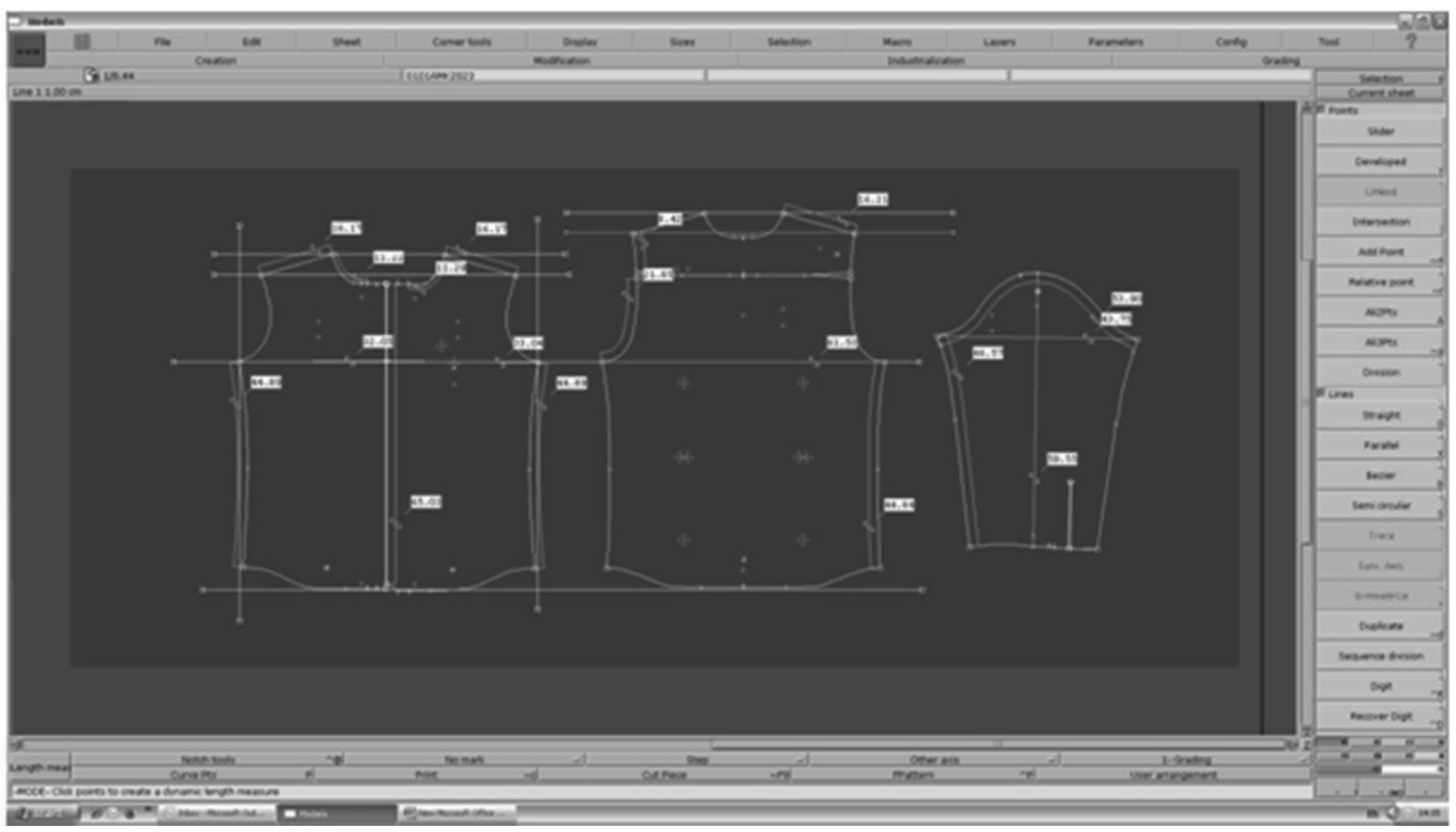

Figure 2: Construction on the basic pattern of the men's shirt

3D garment design

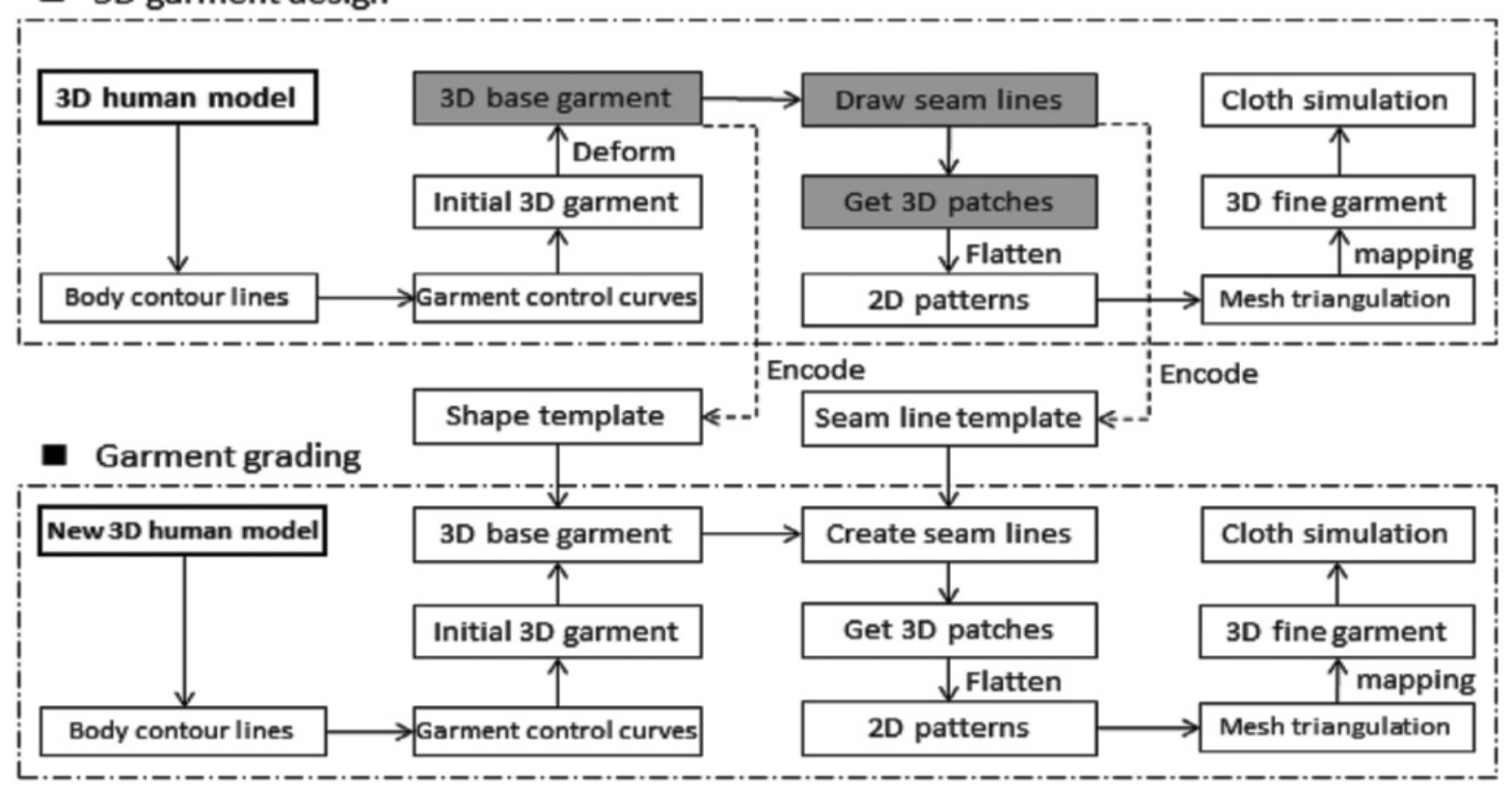

Figure 3: Flowchart of 3D clothing design [16] 
well fit the underlying human body. A surface mapping technique is proposed to create a 3D fine garment model, which is constructed by automatically sewing flattened $2 \mathrm{D}$ patterns using the information of sewing relations and correspondence between 3D surface patches and 2D patterns. Figure 3 shows the flowchart of a 3D garment design [16].

The traditional process of creating a 3D virtual garment starts with the design of $2 \mathrm{D}$ patterns. The patterns are placed around a 3D human body and then stitched together, where cloth simulation is used to generate the final 3D shape.

Figure 4 shows a correspondence between 3D surface patches and 2D patterns with an arrangement point. Arrangement points on the avatar in 3D denote points for positioning parts before sewing. It takes one piece at a time from $2 \mathrm{D}$ and is carried in $3 \mathrm{D}$ where it is placed at an arrangement point marked in blue color.

To design 2D patterns, firstly seam lines will be drawn on the base garment surface, then a 3D surface patch surrounding by seam lines will be searched and flattened into a 2D mesh, and finally the boundary lines of the mesh are generated to form the final pattern. Seam lines are used to define the style of a garment and the shape of 2D patterns. Since seam lines are drawn on the base garment surface manually, and the shape of a $2 \mathrm{D}$ pattern is computed automatically by flattening a 3D surface patch, the method provides a straightforward pattern design approach and alleviates the requirements of knowledge and experience for a pattern designer, shown in Figure 5, 6 and 7 (front, side and back).

Sewing information indicates adjacent relations of $2 \mathrm{D}$ patterns that are sewn together in $3 \mathrm{D}$. Since 2D patterns are obtained by flattening 3D surface patches, the information of adjacency between 2D patterns can be automatically achieved based on the relative positions of corresponding 3D surface patches.

However, two adjacent patterns in 3D space are not necessarily sewn together, so sometimes it is necessary to interactively adjust the automatically established sewing information.

The avatar in Figures 5, 6 and 7 is shown in different postures in front, side and back.

After the transformation of the parts of the men's shirt from 2D to 3D, where the seams to be sewn are marked on the 2D surface, i.e. the finished shirt is obtained on the avatar, the model is checked for deformations in relation to the fit. This is done using strain maps.

Strain Map - Garment's distortion rate due to external stress appears in percentage.

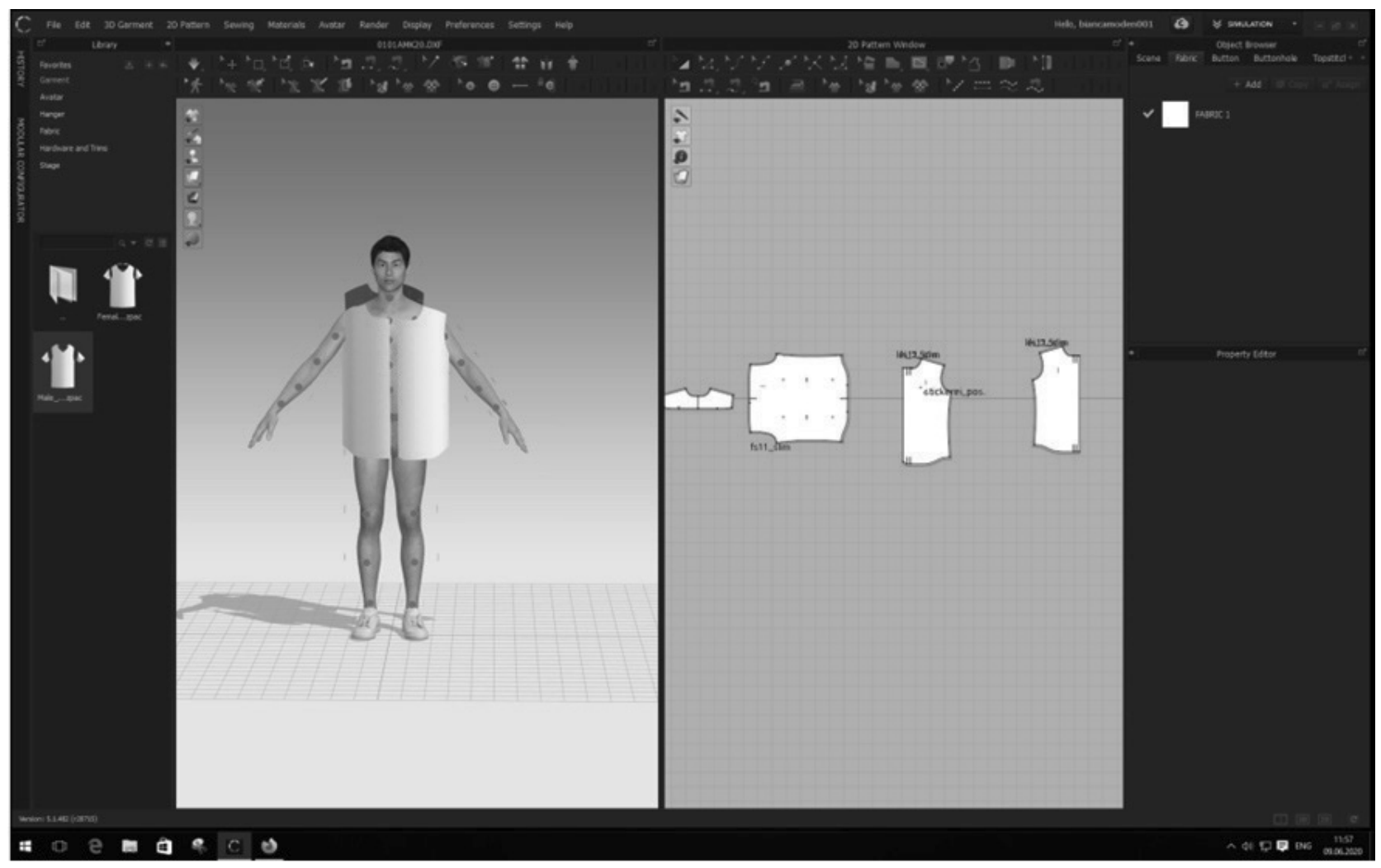

Figure 4: 2D-to-3D transformation with arrangement point 


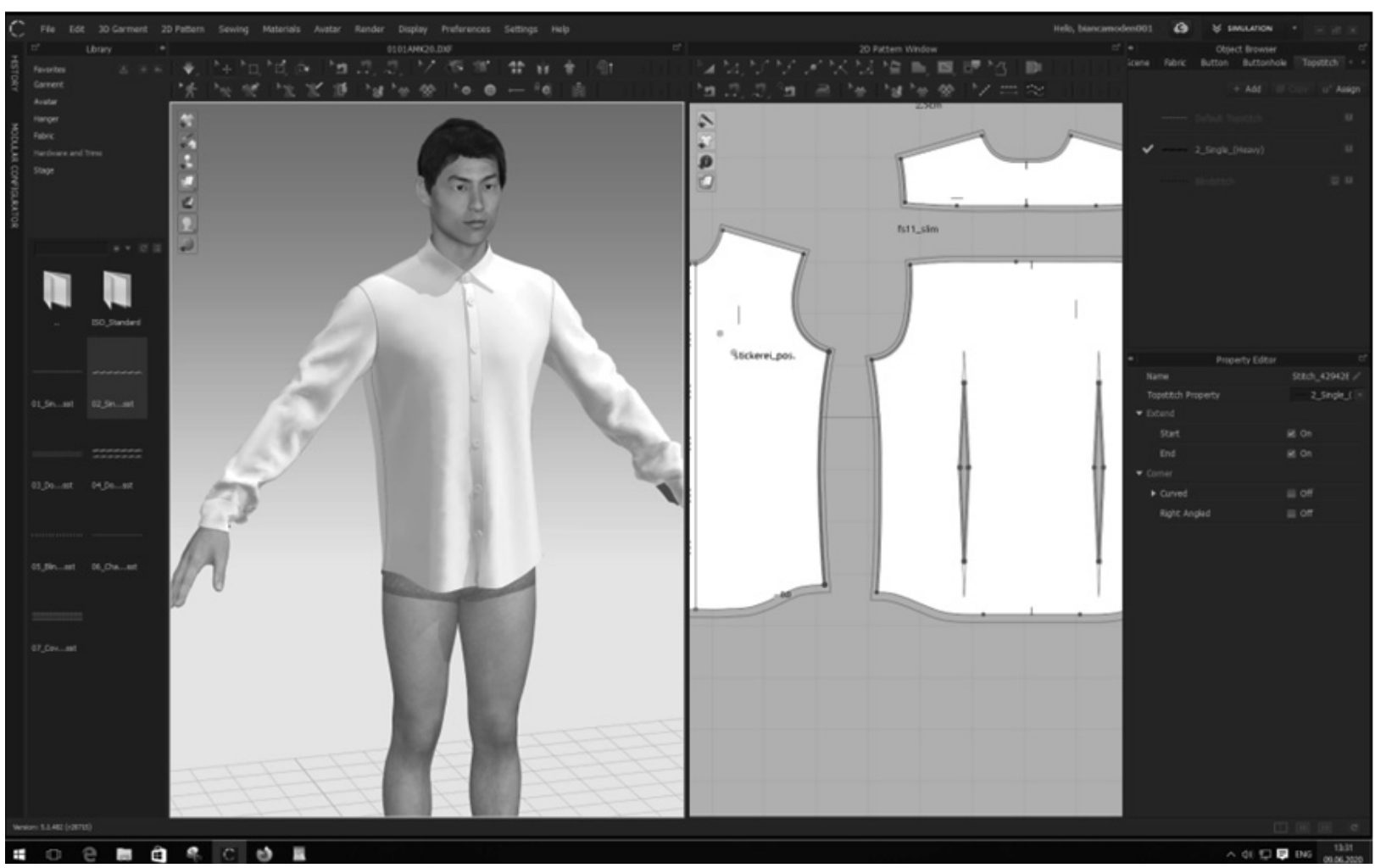

Figure 5: Sewing process on the avatar in 3D on front

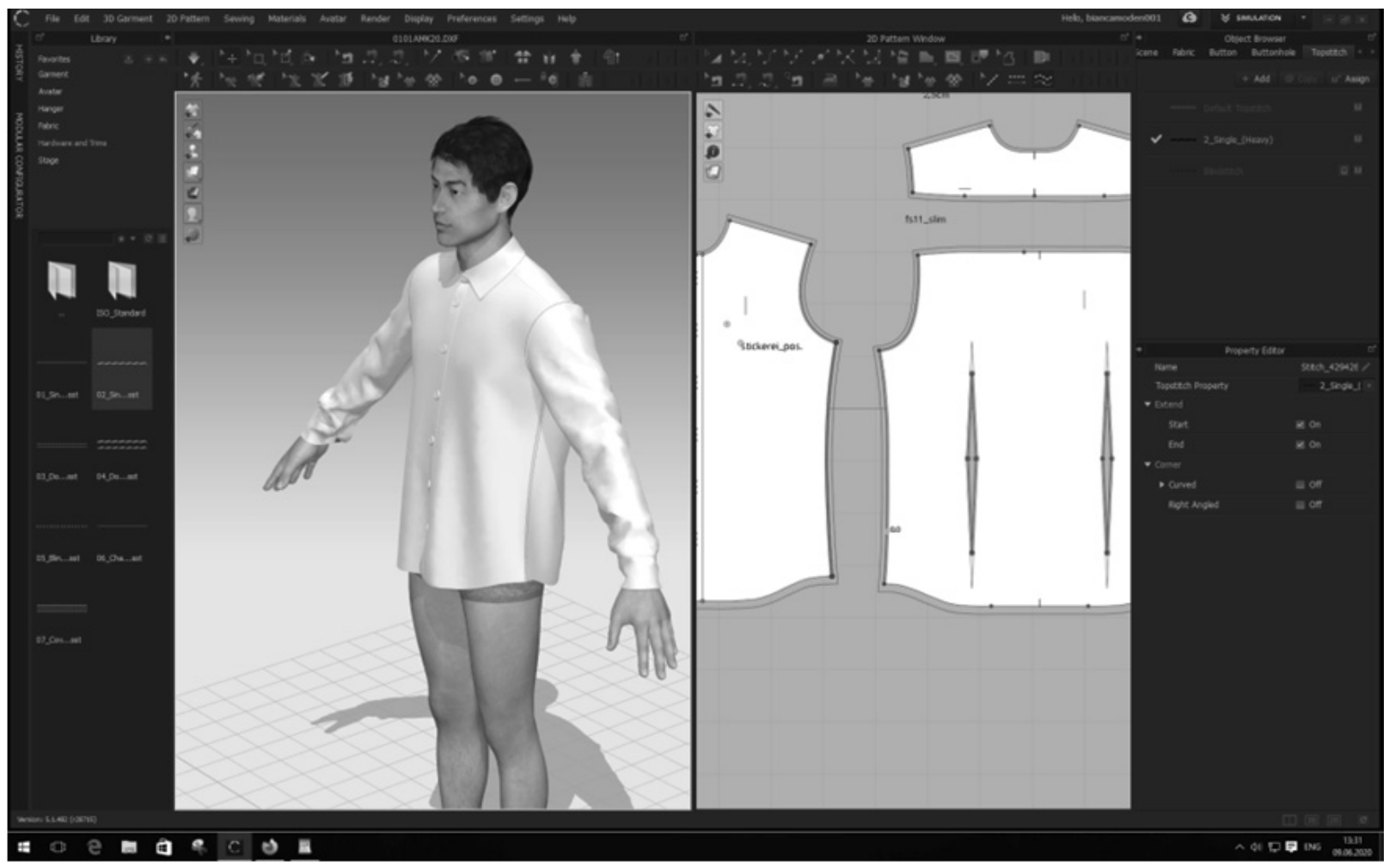

Figure 6: Sewing process on the avatar in 3D on side

Stain Map appears in a total of eight colors: Red indicates $120 \%$ of distortion rate while blue indicates $100 \%$ (no distortion). Numbers in between are expressed as gradation of two color.

In the case of the men's shirt, it can be seen that the red color appears in the area of the armhole sleeves on the front and back, (Figure 8). This may mean that the sleeve in that part is larger in width and does not fit well, i.e. that it has more material than is needed in that part. So immediately go to the correction where this can be corrected, that is, reduce the armhole of the sleeve to $2 \mathrm{D}$ and then check it in 3D. 


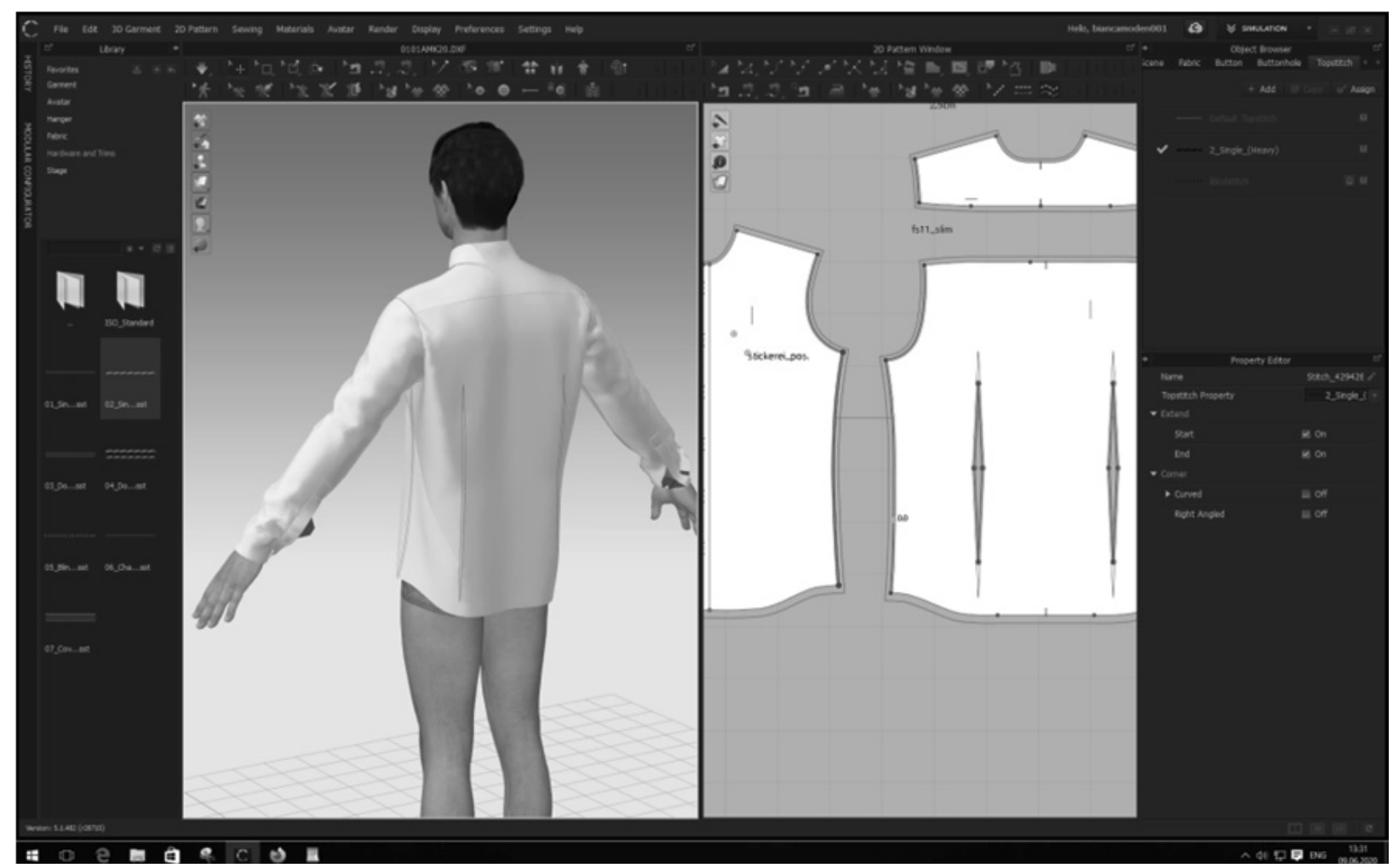

Figure 7: Sewing process on the avatar in 3D on back
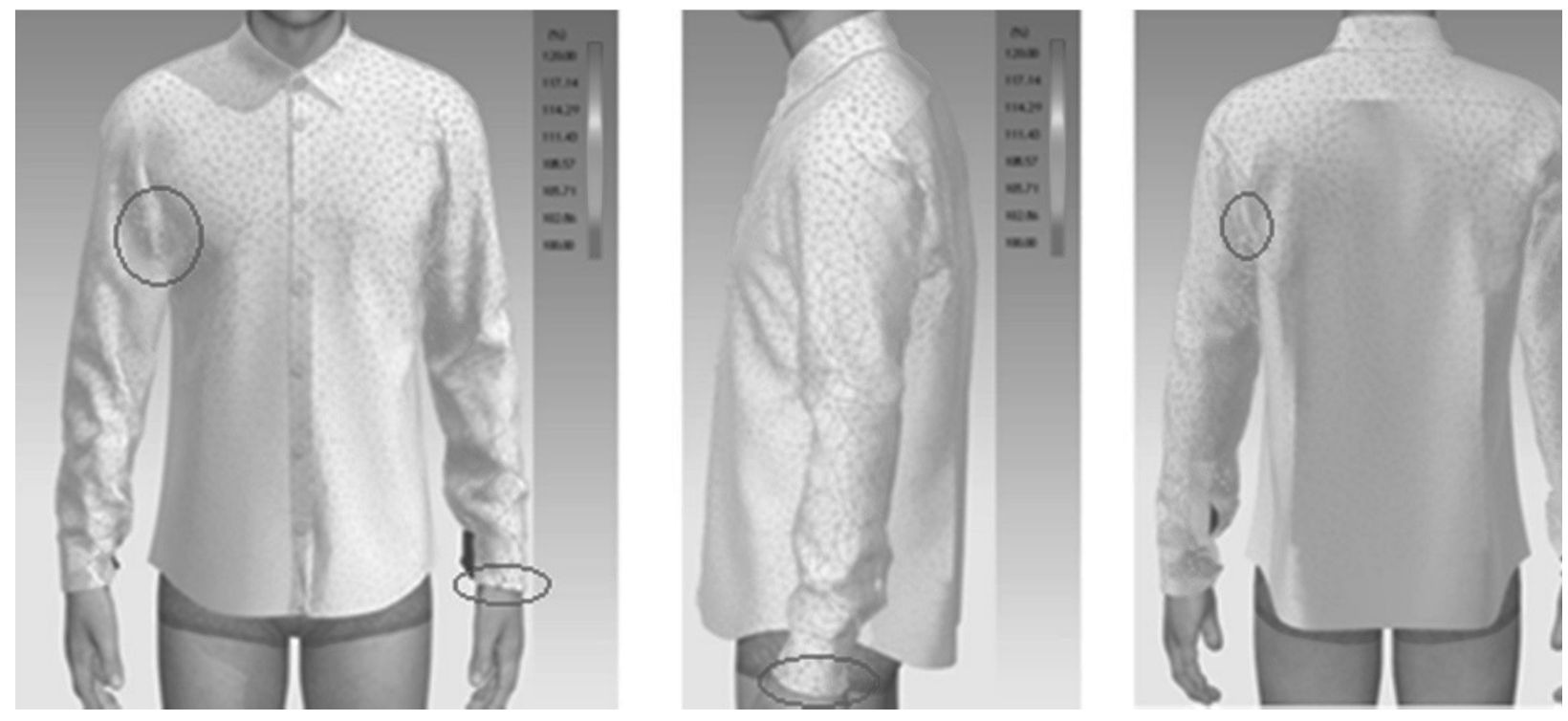

Figure 8: 3D men's shirt with mesh mapping

Also, the red color of the mesh occurs at the hem of the sleeve, which could mean that the cuff is tight or wide. In this case, it can be seen that the cuff does not fit well on the arm. Check and see what the problem is, if there is some distortion then fixes it, and if there is no it can be ignored and not considered a problem.

On the whole, can see that the men's shirt fits well on the avatar, which shows us the strain map or mesh that we get is with equilateral triangles in blue color and there is a slight distortion in the armhole and the length of the cuff. In this way, has got a quick production of a men's shirt not only in 2D but also in 3D, where in that way the production time and sewing of clothes is shortened. Also, from the final garment it can be immediately concluded whether the whole process of its production from construction to manufacture is done well and how the garment will behave on the human body. 


\section{CONCLUSION}

The study of this paper is to make a 2D pattern and 3D simulation of men's shirt. First, the computer construction of the men's shirt model was made on a sketch-based, i.e. a 2D pattern is developed. Secondly, 2D pattern is developed by flattening 3D surface patches, then a 3D fine garment is formed directly based on the information of sewing relations and correspondence between 3D surfaces and 2D patterns.

To cope with rapid fashion changes and also to reduce the costs, there is pressure from the retail sector to shorten product-development as much as possible and also to minimise the investment in physical prototyping. Virtual prototyping is offered as a solution to this problem. Draping the 2D patterns onto a virtual human model to visualise the 3D appearance of the clothing, coupled with a realistic simulation of the material behaviour, provides the opportunity to check fit and pattern flaws so that the initial 2D pattern pieces might be refined. It is claimed by the software suppliers that such an approach will reduce the dependency on physical prototyping, and will shorten the product-development lead time and the associated costs when communicated over the internet platform.

\section{REFERENCES}

[1] Decaudin, P., Julius D., Wither J., Boissieux L., Sheffer A., Cani, M. P. (2006). Virtual garments: A fully geometric approach for clothing design, Computer Graphics Forum, 25, 625-634.

[2] Robson, C., Maharik R., Sheffer A., Carr N. (2011). Context-aware garment modeling from sketches. Computers \& Graphics, 35, 604-613.

[3] Wang, C. C. L., Wang Y., Yuen M. M. F. (2003). Feature based 3D garment design through 2D sketches, Computer-Aided Design, 35, 659-672.

[4] Magnenat-Thalmann, N., Cordier F., Seo H. (2004). Papagianakis G. Modeling of bodies and clothes for virtual environments, Proceedings of International Conference on Cyber worlds, 18th - 20th Nov, 2004, Tokyo, 201-208.

[5] Volino P., Cordier F., Magnenat-Thalmann N. (2005). From early virtual garment simulation to interactive fashion design, Computer-Aided Design, 37(5), 593-608.

[6] Lee J, Nam Y., Cui, M. H., Choi K. M., Choi Y. L. (2007). Fit evaluation of 3D virtual garment, Proceedings of $2^{\text {nd }}$ International Conference on Usability and Inter- nationalization, Part I, HCII, LNCS 4559, July 22nd - 27th, 2007, Beijing, 550-558.

[7] Liu, Y. J., Zhang, D. L., Yuen, M. M. F. (2010). A survey on CAD methods in 3D garment design, Computers in Industry, 61, 576-593.

[8] Turquin, E., Wither, J., Boissieux L., Cani M., Hughes J. (2007). A sketch-based interface for clothing virtual characters, IEEE Computer Graphics and Applications, 27, 72-81.

[9] Brouet, R., Sheffer, A., Boissieux, L., Cani, M. P. (2012). Design preserving garment transfer, Transactions on Graphics, 31(4), 1-36.

[10] Porterfield, A., Lamar T. A. M. (2016). Examining the effectiveness of virtual fitting with 3D garment simulation, International Journal of Fashion Design, Technology and Education, 10(3), 320-330.

[11] Lee, E., Park, H. (2016). 3D Virtual fit simulation technology: strengths and areas of improvement for increased industry adoption, International Journal of Fashion Design, Technology and Education, 10(1), 59-70.

[12] Lage, A., Ancutiene, K. (2017). Virtual try-on technologies in the clothing industry. Part 1: investigation of distance ease between body and garment, The Journal of The Textile Institute, 108(10), 17871793.

[13] Kim, D. E., La-Bat, K. (2013). Consumer experience in using 3D virtual garment simulation technology, The Journal of The Textile Institute, 104(8), 819-829.

[14] Wu Y.Y., Mok P.Y., Kwok Y. L., Fan J.T., Xin J. H. (2011). An investigation on the validity of $3 \mathrm{D}$ clothing simulation for garment fit evaluation, Proceedings of the IMProVe, International conference on Innovative Methods in Product Design, June 15th - 17th, 2011, Venice, Italy.

[15] Paunović, D. (2018). Modern 3D technologies in design of fashion products, Tekstilna Industrija, 66(3), 13-17.

[16] Zhang, D., Liub Y., Wang J., Li J. (2018). An integrated method of 3D garment design, The Journal of the Textile Institute, 9(12), 1595-1605.

\section{Rad primljen: 01.11.2020}

Rad prihvaćen: 14.11.2020. 